\title{
Striking changes in tea metabolites due to elevational effects
}

\author{
Authors: Nicole Kfoury, Joshua Morimoto, Amanda \\ Kern, Eric R. Scott, Colin M. Orians, Selena Ahmed, \\ Timothy Griffin, Sean B. Cash, John Richard Stepp, \\ Dayuan Xue, Chunlin Long, and Albert Robbat Jr.
}

NOTICE: this is the author's version of a work that was accepted for publication in Food Chemistry. Changes resulting from the publishing process, such as peer review, editing, corrections, structural formatting, and other quality control mechanisms may not be reflected in this document. Changes may have been made to this work since it was submitted for publication. A definitive version was subsequently published in Food Chemistry, volume 264, October 2018, DOI\# 10.1016/j.foodchem.2018.05.040.

Kfoury, Nicole, Joshua Morimoto, Amanda Kern, Eric R. Scott, Colin M. Orians, Selena Ahmed, Timothy Griffin, Sean B. Cash, John Richard Stepp, Dayuan Xue, Chunlin Long, and Albert Jr. Robbat. "Striking changes in tea metabolites due to elevational effects." Food Chemistry 264(October 2018): 334-341. DOI:10.1016/j.foodchem.2018.05.040. 


\title{
Striking changes in tea metabolites due to elevational effects
}

\author{
Nicole Kfoury ${ }^{\mathrm{a}, \mathrm{b}}$, Joshua Morimoto ${ }^{\mathrm{a}}$, Amanda Kern ${ }^{\mathrm{b}}$, Eric R. Scott ${ }^{\mathrm{c}}$, Colin M. Orians ${ }^{\mathrm{b}, \mathrm{c}}$, \\ Selena Ahmed ${ }^{\mathrm{d}}$, Timothy Griffin ${ }^{\mathrm{e}}$, Sean B. Cash ${ }^{\mathrm{b}, \mathrm{e}}$, John Richard Stepp ${ }^{\mathrm{f}}$, Dayuan Xue ${ }^{\mathrm{g}}$, \\ Chunlin Long ${ }^{g}$, Albert Robbat Jr. ${ }^{\mathrm{a}, \mathrm{b}, *}$ \\ a Department of Chemistry, Tufts University, Medford, MA 02155, USA \\ ${ }^{\mathrm{b}}$ Tufts University Sensory and Science Center, Medford, MA 02155, USA \\ ${ }^{\mathrm{c}}$ Department of Biology, Tufts University, Medford, MA 02155, USA \\ d Department of Health and Human Development, Montana State University, Bozeman, MT 59717, USA \\ ${ }^{\mathrm{e}}$ Friedman School of Nutrition Science and Policy, Tufts University, Boston, MA 02111, USA \\ ${ }^{\mathrm{f}}$ Department of Anthropology, University of Florida, Gainesville, FL 32611, USA \\ ${ }^{\mathrm{g}}$ College of Life and Environmental Sciences, Minzu University of China, Beijing, China
}

\begin{abstract}
A B S T R A C T
Climate effects on crop quality at the molecular level are not well-understood. Gas and liquid chromatography-mass spectrometry were used to measure changes of hundreds of compounds in tea at different elevations in Yunnan Province, China. Some increased in concentration while others decreased by 100's of percent. Orthogonal projection to latent structures-discriminant analysis revealed compounds exhibiting analgesic, antianxiety, antibacterial, anticancer, antidepressant, antifungal, anti-inflammatory, antioxidant, anti-stress, and cardioprotective properties statistically $(\mathrm{p}=0.003)$ differentiated high from low elevation tea. Also, sweet, floral, honey-like notes were higher in concentration in the former while the latter displayed grassy, hay-like aroma. In addition, multivariate analysis of variance showed low elevation tea had statistically $(\mathrm{p}=0.0062)$ higher concentrations of caffeine, epicatechin gallate, gallocatechin, and catechin; all bitter compounds. Although volatiles represent a small fraction of the total mass, this is the first comprehensive report illustrating how normal variations in temperature, $5^{\circ} \mathrm{C}$, due to elevational effects impact tea quality.
\end{abstract}

\section{Introduction}

The effects of climate on crop yield are well-known (Kang, Khan, \& Ma, 2009; Kurukulasuriya \& Rosenthal, 2013). Less appreciated is the change in crop quality at the molecular level that occurs in response to abiotic (e.g., water availability, temperature, light) pressures (Holopainen \& Gershenzon, 2010). These differences can be investigated by measuring changes in primary and secondary metabolite concentration produced by plants. For example, we (Ahmed et al., 2014) measured a $50 \%$ decrease in the concentration of catechins (wellknown phenolic antioxidants) in tea (Camellia sinensis (L.) Kuntze) harvested from Yunnan Province, China, during the spring to summer transition (low to monsoon rainfalls). In contrast, total polyphenol content and anti-oxidant potential were much higher, meaning other phenolic compounds such as flavones, flavonols, phenolic acids, and their derivatives (Kalili \& de Villiers, 2010) increased in concentration as catechins decreased. Also, striking differences in the composition of volatile secondary metabolites were found. Many increased, others decreased by hundreds of percent, while some exhibited no change in concentration (Kowalsick et al., 2014). Nearly 40\% of the metabolites detected exhibit organoleptic properties and/or have nutritional benefit.

Crops grown at different elevations also differ in quality (Trad, Gaaliche, Renard, \& Mars, 2013). In tea, for example, farmers associate aromatic quality with higher elevation teas (Ahmed \& Stepp, 2012), since they exhibit sweet, floral, honey-like characteristics compared to green, earthy, hay-like notes in low elevation tea (Mahanta, Baruah, Owour, \& Murai, 1988; Owuor, Obaga, \& Othieno, 1990). For catechins and methylxanthines, reports are inconsistent. Some researchers report higher concentrations in high altitude tea whereas others measured higher concentrations in low elevation tea (Chen et al., 2010; Chen, Yang, Lee, Wu, \& Tzen, 2014; Han et al., 2017; Zhang, Suen, Yang, \& Quek, 2018).

Review of the medical literature reveals no studies have been conducted based on differences in pre- vs. monsoon or high vs. low elevation teas presumably due to the fact that little is known about sample 
differences at the molecular level. Although the volatile metabolites represent a small fraction of the total mass, findings indicate that volatile tea extracts have proven health benefits (Li, Kawasaki, Tomita, \& Kawai, 2017; Takahashi et al., 2014). With this in mind, the aim of this paper is to investigate tea quality differences based on elevational effects by collecting tea from the same farm on two different mountains in Yunnan Province, China. Automated, sequential, 2-dimensional gas chromatography/mass spectrometry (GC-GC/MS) was used to obtain a comprehensive metabolomic profile of volatile secondary metabolites in tea. In addition to known sensory compounds, sample portions containing unidentifiable compounds were screened by GC-GC/MSolfactometry to determine if they were sensory active. Once the library was made, the relative differences in GC/MS peak area for each compound between high and low elevation samples were calculated. In addition, liquid chromatography/mass spectrometry (LC/MS) was used to quantify catechins and some methylxanthines.

\section{Materials and methods}

\subsection{Materials}

Tea samples were collected in 2013 from two different mountains, (Jinuo, Mengla County, southeast and Bulang, Menghai County, southwest), in Yunnan Province, China. Samples were collected from each mountain at high $(1400 \mathrm{~m})$ and low $(600 \mathrm{~m})$ elevations in the first and third (Jinuo only) weeks of May. The high elevation sites were $\sim 5.3^{\circ} \mathrm{C}$ cooler than the low elevation sites (NOAA, 2017). On each plant the terminal bud plus two leaves were harvested from five different plants per plot. Samples were collected from four plots each day for three consecutive days. Since no statistical difference between plots was observed in catechin and methylxanthine concentrations in our earlier study (Ahmed et al., 2014), samples from within the plots were homogenized to create each day's samples. No plant was sampled more than once. Leaves were minimally processed in the field by microwave to stop enzymatic oxidation (Ahmed et al., 2014; Kowalsick et al., 2014). The dried leaves were sealed in plastic bags and shipped to Tufts University, where they were stored at $-5{ }^{\circ} \mathrm{C}$ until analyzed.

$\mathrm{C}_{7}-\mathrm{C}_{30} n$-alkanes, sodium sulfate, theobromine (TB), paraxanthine (98\%), catechol ( $\geq 99 \%)$, formic acid, methanol, and methylene chloride were purchased from Sigma-Aldrich (St. Louis, MO, USA). Naphthalene- $\mathrm{d}_{8}$ was purchased from Restek (Bellefonte, PA, USA). Caffeine was purchased from Alfa Aesar (Ward Hill, MA, USA). (-)-Gallocatechin (GC, > 99\%) and (-)-catechin gallate (CG, > 98\%) were purchased from Indofine (Hillsborough Township, NJ, USA). (-)-Epigallocatechin (EGC, 94.6\%), (-)-epicatechin (EC, 96.2\%), (-)-epigallocatechin gallate (EGCG, 94.0\%), (-)-epicatechin gallate (ECG, 96.0\%), (+)-catechin (C, 94.9\%), and (-)-gallocatechin gallate (GCG, 98.4\%) were purchased from ChromaDex (Irvine, CA, USA). $18 \mathrm{M} \Omega$ water was obtained from a Hydro Picopure 3 faucet system (Durham, NC, USA). A total of 250 reference standards were purchased from Sigma-Aldrich (St. Louis, MS, USA), Alfa Aesar (Ward Hill, MA, USA), TCI (Tokyo, Japan), Acros Organics (Pittsburgh, PA, USA), MP Biomedicals (Santa Ana, CA, USA), and Fisher Scientific (Pittsburgh, PA, USA). Polyvinylidene fluoride syringe filters were purchased from MilliporeSigma (Burlington, MA, USA).

\subsection{Sample preparation}

For GC/MS analysis, each sample was extracted using simultaneous distillation-extraction (Kowalsick et al., 2014) using $10 \mathrm{~g}$ of tea, brewed in $100 \mathrm{~mL}$ of deionized water at $90^{\circ} \mathrm{C}$ and then allowed to cool in a sealed container for $30 \mathrm{~min}$. The filtered infusion and $12 \mathrm{~mL}$ of methylene chloride were simultaneously distilled for $2 \mathrm{~h}$ at $100{ }^{\circ} \mathrm{C}$ and $60^{\circ} \mathrm{C}$, respectively. Anhydrous sodium sulfate was used to remove water from the extract, after which was concentrated to $500 \mu \mathrm{L}$ under a stream of purified nitrogen.
For LC/MS analysis, sample preparation was adapted from the procedure described by Ahmed et al. (2014). $20 \mathrm{mg}$ of each sample was extracted with $1 \mathrm{~mL}$ of $80 \%$ methanol/water v/v in a $1.5 \mathrm{~mL}$ microcentrifuge tube. Samples were sonicated for $30 \mathrm{~min}$ and then centrifuged at $13,000 \mathrm{rpm}$ for $1 \mathrm{~min}$. A $0.45 \mu \mathrm{m}$ polyvinylidene fluoride syringe filter was used to remove particulates from the supernatant, which was subsequently diluted five-fold for the methylxanthines and catechins and ten-fold for epicatechin with $80 \%$ methanol/water solution.

\section{3. $G C-G C / M S$ and $G C / M S$ conditions}

Representative samples from each mountain at the two elevations were analyzed by automated sequential 2-dimensional GC-GC/MS to produce the metabolite library. Instrument configuration and heartcutting procedure were described by Kowalsick et al. (2014). Briefly, the first GC (Agilent 6890, Santa Clara, CA, USA) housed column 1 (C1, $30 \mathrm{~m} \times 250 \mu \mathrm{m} \times 0.25 \mu \mathrm{m}$ Rtx-Wax, Restek, Bellefonte, PA, USA) and was equipped with a flame ionization detector (FID). The temperature of $\mathrm{C} 1$ was programmed to hold at $40^{\circ} \mathrm{C}$ for $1 \mathrm{~min}$, then ramped to $240{ }^{\circ} \mathrm{C}$ at $5{ }^{\circ} \mathrm{C} / \mathrm{min}$. $\mathrm{C} 1$ was connected to a CIS4 inlet (Gerstel, Mülheim an der Ruhr, Germany), operating in splitless mode, on one end and to a 5 -port crosspiece (Gerstel, Mülheim an der Ruhr, Germany) on the other. The second oven contained column 2 (C2, $30 \mathrm{~m} \times 250 \mu \mathrm{m} \times 0.25 \mu \mathrm{m}$ Rxi-5MS, Restek, Bellefonte, PA, USA), which was connected to the crosspiece through a cryogenic freeze trap (CTS1, Gerstel, Mülheim an der Ruhr, Germany) on one end and to an Agilent (Santa Clara, CA, USA) 5975 mass spectrometer on the other. The oven temperature was held at $40^{\circ} \mathrm{C}$ for $1 \mathrm{~min}$, and then increased to $280^{\circ} \mathrm{C}$ at a rate of $5^{\circ} \mathrm{C} / \mathrm{min}$. Both columns operated at $1.2 \mathrm{~mL} / \mathrm{min}$ constant helium flow. The ion source and quadrupole temperatures were $230^{\circ} \mathrm{C}$ and $150{ }^{\circ} \mathrm{C}$, respectively. The MS was scanned from 50 to $350 \mathrm{~m} / \mathrm{z}$. The ionization potential was $70 \mathrm{eV}$. A multipurpose sampler (MPS, Gerstel, Mülheim an der Ruhr, Germany) automatically injected $2 \mu \mathrm{L}$ of sample, and a multi-column switching device (MCS, Gerstel, Mülheim an der Ruhr, Germany) supplied countercurrent flow to the crosspiece. A heartcut was made every minute for a total of 40 heartcuts per sample. Each heartcut required a separate injection that only occurred after each preceding heartcut eluted from both columns. The total analysis time for one sample was 3.5 days.

Three replicate samples from each mountain, elevation and sampling period were analyzed by GC/MS to determine the relative amounts of each analyte in the samples based on a $1 \mu \mathrm{L}$ injection volume. Concentration differences were calculated as the difference in relative peak areas (RPA) compared to the internal standard, naphthalene- $d_{8}$. A standard mixture of $C_{7}-C_{30} n$-alkanes was used to calculate the retention index (RI) for each compound. Reference standards, when available, were used to provide positive confirmation of compound identity.

\subsection{GC-GC/MS-olfactometry conditions}

By reversing the two columns, the GC-GC/MS-olfactometry analysis served two purposes. First, the analysis confirmed compound identity by comparing the analyte and reference compound mass spectrum and retention index on the polar column for positively identified compounds as well as tentatively identified compounds using commercial databases and literature data. Low thermal mass columns, Agilent HP5MS (30 $\times 250 \mu \mathrm{m} \times 0.25 \mu \mathrm{m}$, Santa Clara, CA, USA) and Agilent HP-INNOWax $(30 \mathrm{~m} \times 250 \mu \mathrm{m} \times 0.25 \mu \mathrm{m}$, Santa Clara, CA, USA), were connected by a Deans switch (Agilent, Santa Clara, CA, USA). The analytical column, HP-INNOWax was connected to an Agilent (Santa Clara, CA, USA) 5975C MS and Gerstel's (Mülheim an der Ruhr, Germany) ODP 3 sniffing port by a 3-way splitter (Agilent, Santa Clara, CA, USA). The temperature programs and MS operating conditions were described in Section 2.3. Second, tea samples were screened by 
trained and certified sensory analysts at Tufts University Sensory and Science Center (TUSSC) to assess the odor characteristics of the analytes. The method employed was modified from the American Society for Testing and Materials Flavor Profile Method (ASTM, 1992) and is a descriptive sensory analysis, based on a 7-point intensity scale, where trained panelists qualify aroma using objective terms based on reference standards.

\subsection{Data analysis software}

New data analysis software developed by Robbat and sold by Gerstel was used to automatically inspect GC-GC/MS data to produce an environmental tea database, which could be used with spectral deconvolution to provide target compound analysis by GC/MS (Robbat, Kfoury, Baydakov, \& Gankin, 2017). The 40 heartcut data files were analyzed by inspecting each peak in the data file to determine mass spectral constancy across the peak. If constant, the software recorded retention times, mass spectra, 3-5 target ions and their relative abundances for each peak. The software compared the sample data to reference compound or commercial libraries (e.g., NIST, Wiley, Adams) and literature (Babushok, Linstrom, \& Zenkevich, 2011) to provide positive or tentative identification. Then, compound name, CAS\#, and RI were added to the database. If neither positive nor tentative identification was possible, the same information was uploaded into the database with a numeric identifier as opposed to compound name and CAS\#.

If mass spectra varied across the peak, the software searched for 3-5 invariant scans ( $\pm 20 \%$ ), averaged their mass spectra, and then subtracted it from the total ion current (TIC) signal. Once subtracted, the residual ion signals were automatically inspected to determine if the resulting peak scans were constant or approximated background noise. If constant, the mass spectrum of the second compound was subjected to the treatment described above, with associated compound information uploaded into the database. If not (unresolved peak), the software repeated the subtraction process until the residual signal approximated background signal. If the resulting signal did not meet the user-defined criteria, see below, no additional information was obtained.

Four parameters were chosen as the compound acceptance criteria. First, the mass spectrum must be constant for at least five consecutive scans, i.e., $\leq 20 \%$ deviation. Second, the scan-to-scan variance (SSV) must be $<5$. The SSV algorithm calculates the relative error by comparing the mass spectrum at each peak scan against one another. The smaller the difference, the closer SSV is to zero, the better the spectral agreement. Third, the Q-value must be $\geq 93$. The Q-value measures the total ion ratio deviation of the absolute value of the expected minus observed ion ratios divided by the expected ion ratio times 100 for each ion across the peak. The closer the value is to 100 , the higher the certainty between library and sample spectra. Finally, the Q-ratio must be $\leq 20 \%$ deviation. The Q-ratio compares the ratio of the molecular ion intensity to confirming ion intensities across the peak. The software assigns a compound name from libraries or numerical identifier when all compound acceptance criteria are met.

\subsection{LC/UV-MS conditions}

Target compounds were quantified with an Agilent (Santa Clara, CA, USA) 1260 series LC consisting of a binary pump, an autosampler cooled to $4{ }^{\circ} \mathrm{C}$, a thermostatted column compartment with columnswitching valve, a diode array detector (DAD), and an Agilent 6120 quadrupole mass spectrometer with electrospray ionization (ESI) source. The mobile phase was $0.05 \%$ formic acid in water ( $\mathrm{v} / \mathrm{v}$, solvent A) and $0.05 \%$ formic acid in methanol ( $\mathrm{v} / \mathrm{v}$, solvent $\mathrm{B}$ ). The injection volume was $1 \mu \mathrm{L}$. DAD spectra were acquired from 190 to $500 \mathrm{~nm}$, with eluting compounds monitored at $280 \mathrm{~nm}$. Electrospray parameters were: drying gas flow rate $12 \mathrm{~L} / \mathrm{min}$, gas temperature $350{ }^{\circ} \mathrm{C}$, nebulizer pressure $35 \mathrm{psig}$, capillary voltage $3000 \mathrm{~V}$, and fragmentation voltage $120 \mathrm{~V}$.

Methylxanthines were separated on an Agilent (Santa Clara, CA,

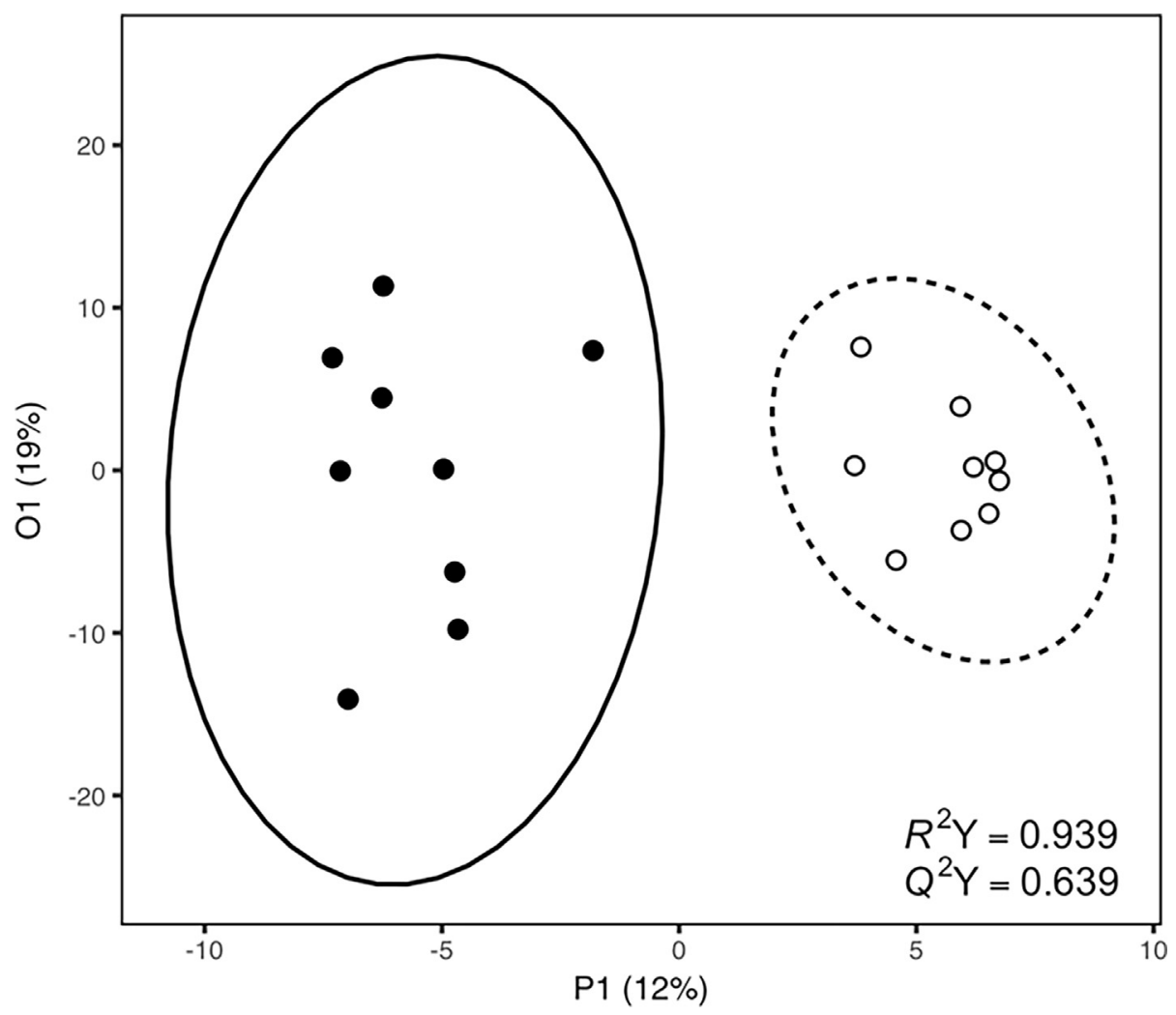

Fig. 1. OPLS-DA statistical analysis of volatiles from high (filled) and low (unfilled) elevation teas. 
Table 1

Statistically important metabolites in high and low elevation tea.

\begin{tabular}{|c|c|c|c|c|c|c|}
\hline No. & Compound & VIP & p-value & \% Diff. & Aroma & Health Property \\
\hline & High Elevation & & & & & \\
\hline 176 & 1-Ethyl-1H-pyrrole-2-carboxaldehyde & 2.479 & 0.0002 & 51 & Roasted, smoky ${ }^{\mathrm{a}}$ & \\
\hline 127 & $m$-Xylene & 2.260 & 0.001 & 49 & Plastic $^{\mathrm{a}}$ & \\
\hline 128 & $p$-Xylene & 2.254 & 0.001 & 48 & Sweet, grain ${ }^{\mathrm{b}}$ & \\
\hline 278 & 2-Cyclohexen-1-ol & 2.005 & 0.005 & - & Caramelized, floral $^{\mathrm{c}}$ & \\
\hline 178 & Benzeneacetonitrile & 1.960 & 0.0008 & 50 & Floral $^{\mathrm{d}}$ & \\
\hline 44 & (Z)-Jasmone & 1.943 & 0.0002 & 60 & Jasmine, floral $^{\mathrm{a}}$ & Antibacterial $^{\mathrm{g}}$ anticancer $^{\mathrm{h}}$ \\
\hline 146 & $\alpha$-Ionene & 1.930 & 0.02 & 48 & Floral, violet $\mathrm{e}^{\mathrm{e}}$ & \\
\hline 266 & (2E)-Hexenol & 1.928 & 0.005 & 72 & Green, leafy, fruity ${ }^{\mathrm{a}}$ & \\
\hline 216 & 7 & 1.888 & 0.01 & 37 & & \\
\hline 52 & (E)-Caryophyllene & 1.885 & 0.008 & 47 & Green, spicy, woody ${ }^{\mathrm{a}}$ & Analgesic $^{\mathrm{i}, \mathrm{k}}$ anticancer ${ }^{\mathrm{i}}$ antianxiety, antidepressant ${ }^{\mathrm{j}}$ anti-inflammatory ${ }^{\mathrm{k}}$ \\
\hline 184 & 2-Acetylfuran & 1.808 & 0.01 & 43 & Sweet, balsamic ${ }^{\mathrm{a}}$ & \\
\hline 76 & (3Z)-Hexenol & 1.778 & 0.02 & 26 & Green, grassy ${ }^{\mathrm{a}}$ & Antinociceptive, anti-fatigue ${ }^{1}$ anti-stress ${ }^{\mathrm{m}}$ \\
\hline 260 & 65 & 1.654 & 0.02 & 53 & & \\
\hline 287 & 6 & 1.625 & 0.03 & - & & \\
\hline 70 & Manool & 1.589 & 0.03 & 59 & & Antibacterial, antifungal, anti-inflammatory ${ }^{n}$ \\
\hline 213 & 1 & 1.560 & 0.05 & 30 & & \\
\hline 125 & 5,5-Dimethyl-1-ethyl-1,3-cyclopentadiene & 1.558 & 0.03 & 32 & & \\
\hline 58 & $\alpha$-Calacorene & 1.537 & 0.02 & 58 & Woody $^{\mathrm{a}}$ & Antibacterial, antioxidant $^{\circ}$ \\
\hline 172 & 1-Ethyl-1H-pyrrole & 1.514 & 0.04 & 75 & Burnt $^{\mathrm{a}}$ & \\
\hline 59 & Cadalene & 1.498 & 0.03 & 71 & & Antibacterial, antioxidant ${ }^{\circ}$ \\
\hline 144 & Theaspirane & 1.347 & 0.02 & 44 & tea, herbal, honey ${ }^{\mathrm{a}}$ & \\
\hline 229 & 25 & 1.328 & 0.02 & 27 & & \\
\hline \multirow[t]{2}{*}{245} & 47 & 1.320 & 0.04 & 43 & & \\
\hline & Low Elevation & & & & & \\
\hline 268 & 2,6-Dimethyl-3,7-octadiene-2,6-diol & 2.255 & 0.001 & - & Fruity, herbal ${ }^{\mathrm{e}}$ & \\
\hline 257 & 66 & 1.906 & 0.01 & -86 & & \\
\hline 97 & (2E,4Z)-Heptadienal & 1.674 & 0.01 & -112 & Fried $^{\mathrm{a}}$ & \\
\hline 29 & trans-Linalool oxide (pyranoid) & 1.620 & 0.02 & -84 & Woody, fresh ${ }^{\mathrm{a}}$ & \\
\hline 107 & Cyclohexanone & 1.590 & 0.02 & -95 & Minty ${ }^{\mathrm{a}}$ & \\
\hline 302 & 72 & 1.509 & 0.01 & - & & \\
\hline 275 & Isovaleric acid & 1.269 & 0.05 & -123 & Cheesy, rancid ${ }^{\mathrm{a}}$ & \\
\hline 283 & 2,5-bis(1,1-dimethylethyl)phenol & 1.448 & 0.03 & -157 & & \\
\hline 50 & Dihydroactinidiolide & 1.398 & 0.02 & -96 & Fruity, woody ${ }^{\mathrm{a}}$ & \\
\hline 232 & 30 & 1.398 & 0.02 & -323 & & \\
\hline 305 & 76 & 1.375 & 0.01 & - & & \\
\hline 293 & 27 & 1.256 & 0.02 & -93 & & \\
\hline 242 & 43 & 1.217 & 0.008 & -199 & & \\
\hline 202 & 2,3-Dihydrobenzofuran & 1.091 & 0.02 & -154 & Green, herbal ${ }^{\mathrm{f}}$ & \\
\hline
\end{tabular}

Notes:

1. S-DA criteria used to determine compound differences between high and low elevation teas: VIP $>1.0$ and $\mathrm{p}$ value $<0.05$.

2. $\%$ Diff. $=[($ High-Low $) /$ High $] \times 100$.

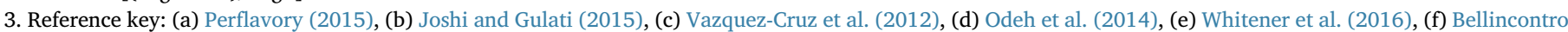

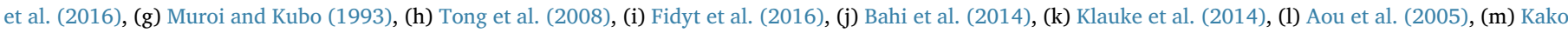
et al. (2008), (n) Olivier and Van Wyk (2013), and (o) Rossi et al. (2011).

4. Numbers in the compound column refer to unknown analytes.

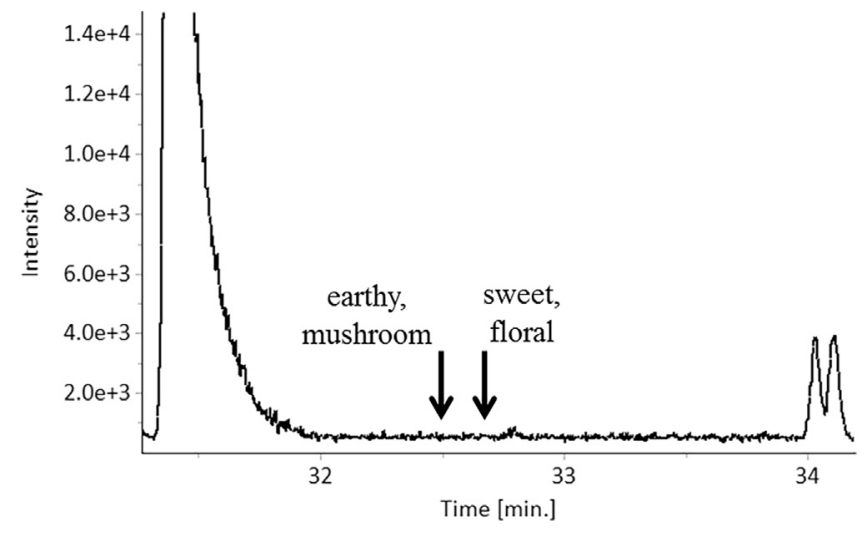

Fig. 2. GC-GC/MS-olfactometry analysis of heartcut 17-18 min.

USA) Eclipse Plus C18 reverse phase column $(100 \times 2.1 \mathrm{~mm}, 3.5 \mu \mathrm{m})$. The flow rate was $0.5 \mathrm{~mL} / \mathrm{min}$. The solvent program was $16 \%$ B for $7 \mathrm{~min}$, then ramped to $100 \%$ over $1 \mathrm{~min}$ and then held constant for $5 \mathrm{~min}$. A $15 \mathrm{~min} 16 \%$ B re-equilibration time established initial operating conditions before the next sample was analyzed. Mass spectra were acquired in positive ion mode from 100 to $220 \mathrm{~m} / \mathrm{z}$. Catechins were separated on a Phenomenex (Torrance, CA, USA) Synergi Polar-RP column $(250 \times 4.6 \mathrm{~mm}, 4 \mu \mathrm{m})$. The flow rate was $1.0 \mathrm{~mL} / \mathrm{min}$. The solvent program was $40 \%$ B for $5.5 \mathrm{~min}$, ramped to $45 \%$ B in $1 \mathrm{~min}$, then held isocratic for $6 \mathrm{~min}$, which was then ramped to $100 \% \mathrm{~B}$ in $0.5 \mathrm{~min}$ and held constant for $7 \mathrm{~min}$. A $15 \mathrm{~min}$ re-equilibration time was established prior to each sample injection. Mass spectra were acquired in negative ion mode using time-based, selected-ion monitoring of four ion groups: group 1, from 0 to $4.90 \mathrm{~min}, 305,306,341,611,612 \mathrm{~m} / z$; group 2, from 4.90 to $6.65 \mathrm{~min}, 108,109,110,289,290,335,357$, $579 \mathrm{~m} / z$; group 3, from $6.65 \mathrm{~min}$ to $9.00 \mathrm{~min}, 108,109,110,169,457$, 458, 459, 493, $503 \mathrm{~m} / \mathrm{z}$; and group 4, 9.00 to $12.50 \mathrm{~min}, 441,442,477$, $487,509 \mathrm{~m} / \mathrm{z}$.

\subsection{LC/MS quantitation of catechins and methylxanthines}

5-Point calibration curves were produced for methylxanthines (TB and caffeine) from 5 to $340 \mu \mathrm{g} / \mathrm{mL}$ and for catechins (EGC, EC, EGCG, ECG, GC, C, GCG, and CG) from 3 to $495 \mu \mathrm{g} / \mathrm{mL}$. Paraxanthine and catechol were used as internal standards for methylxanthines and 


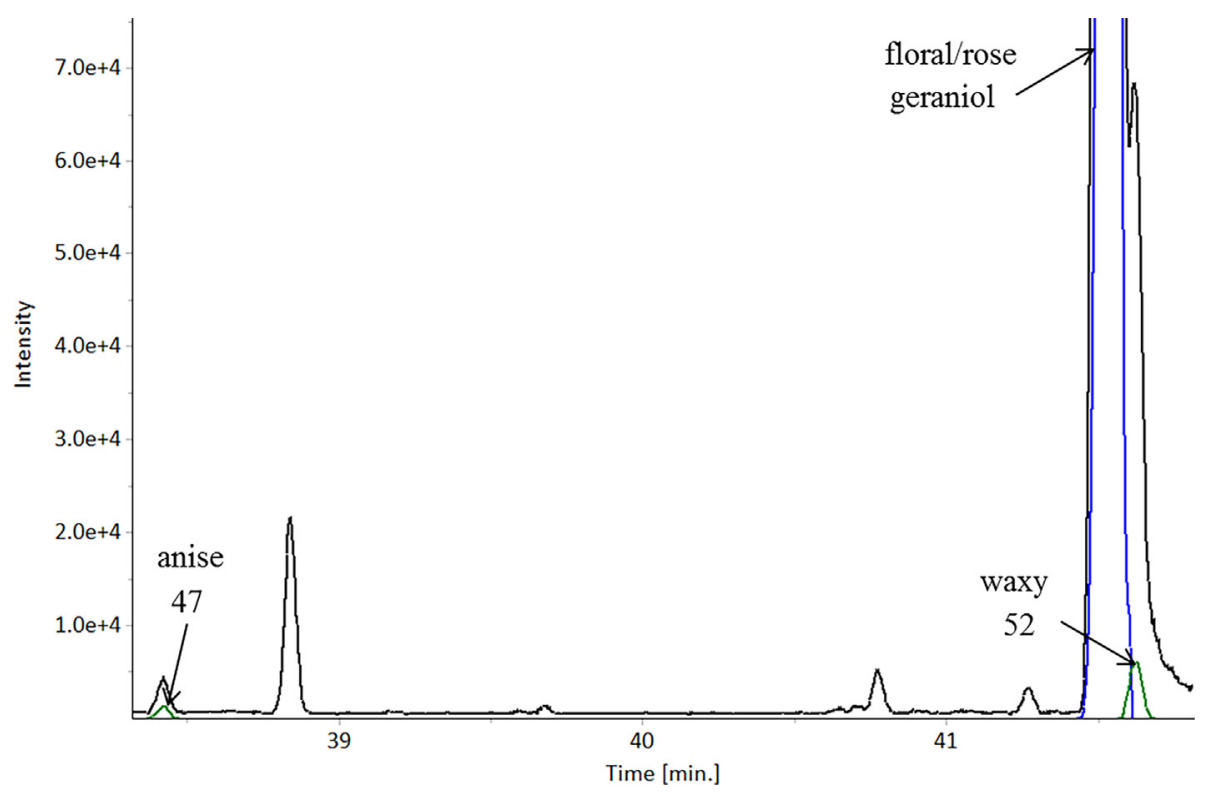

Fig. 3. GC-GC/MS-olfactometry analysis of heartcut $19-20 \mathrm{~min}$.

catechins, respectively. The peak areas at $m / z[\mathrm{M}-\mathrm{H}]^{-}$for catechins and $m / z[\mathrm{M}+\mathrm{H}]^{+}$for methylxanthines were used to quantify analytes. Concentrations were calculated as follows: $\frac{A_{i}}{A_{I S}}=m\left(\frac{C_{i}}{C_{I S}}\right)+b$, where subscripts $i$ and $I S$ refer to the calibrants and internal standards. Calibration curves were acceptable when the correlation coefficient was greater than 0.99 . Target compounds were identified by comparing sample and reference (calibrants) spectra and retention times using Ion Analytics.

\subsection{Statistical analysis}

All statistics were conducted in R (R, 2014). For GC/MS, the ropls Rpackage (Thèvenot, Roux, Xu, Exan, \& Junot, 2015) was used to perform orthogonal projection to latent structures-discriminant analysis (OPLS-DA) of autoscaled (mean-centered and unit-variance scaled) relative peak areas for each compound to evaluate separation space between high and low elevation teas. The quality of the OPLS-DA model is described by $R^{2}$ and $Q^{2}$. $R^{2}$ measures the degree of fit of data to the model. A 7-fold cross validation was used to produce $\mathrm{Q}^{2}$, which measures the predictability of the model. The sampling distribution of the estimates was assessed through a bootstrapping technique based on 1000 permutations of the class labels. The p-value was produced by calculating the proportion of models with random permutations of $\mathrm{Q}^{2}$ greater than the $\mathrm{Q}^{2}$ value of the model made with actual data. Statistical significance was determined using a cutoff of $\alpha=0.05$. Metabolites with a variable influence on projection (VIP) $>1.0$ and statistically different between groups (Mann-Whitney test, $\mathrm{p}<0.05$ ) were considered the strongest contributors to differences in tea metabolite chemistry at different elevations. For LC/MS, one-way multivariate analysis of variance (MANOVA) using elevation as the dependent variable and follow-up ANOVAs were made to determine statistically significant differences $(p<0.05)$ in catechin and methylxanthine concentrations at the two elevations.

\section{Results and discussion}

\subsection{Total volatile metabolomic profile}

A total of 406 compounds were detected by GC-GC/MS. Of these, we confirmed 144 of 259 compounds identified using reference standards. An additional 92 compounds were identified based on their 2- column (5\% phenyl-methylpolysiloxane and polyethylene glycol phases) retention index match and mass spectra comparisons with literature and/or commercial libraries. The remaining compounds were identified by RI on one column and/or MS matches. Although some would argue that retention data and corresponding mass spectra are not considered positive identification, the lack of available reference compounds is limiting when conducting total metabolomic investigations.

To assess the quantitative difference between elevations, samples were analyzed by GC/MS, which limited the mass injected to one-half that of GC-GC/MS due to column and/or MS overload. This resulted in the detection of 305 metabolites. Of these, we identified 230 compounds, confirmed 137 of them by reference standards, which means 71 metabolites were assigned a numerical identifier (Supplementary Tables S1 and S2). Approximately half of the metabolites differed in concentration, 85 were higher in concentration at $1400 \mathrm{~m}$ and 78 at $600 \mathrm{~m}$, with 142 exhibiting no change in concentration, i.e., the percent difference was \pm 20 . Of those that increased in concentration at high elevation, pentacosane represented $11.5 \%$ of the total RPA. Pentacosane, a major component of leaf wax, is known to increase in concentration at higher altitudes due to lower temperatures (Shepherd \& Griffiths, 2006). For low elevation tea, 2,3-dihydrobenzofuran was $16.4 \%$ of the total RPA. This compound is described as green (grassy) and herbal, which is consistent with farmer perceptions of lower quality tea (Bellincontro et al., 2016). Of the total detectable metabolites, 262 were common in all samples with the remainder missing in at least one sample. Five metabolites were found only in high elevation teas and, nine in low elevation teas.

\subsection{Effects of elevation on tea chemistry}

To ensure sampling events did not influence our findings, OPLS-DA (volatiles, $\mathrm{p}=0.05$ ) and MANOVA (non-volatiles, $\mathrm{p}=0.14$ ) analyses revealed the collection of high and low elevation samples during week 1 had metabolite concentrations that were statistically the same as week 3. OPLS-DA was used to evaluate the difference in volatile metabolite concentrations between teas grown at $1400 \mathrm{~m}$ and $600 \mathrm{~m}$. The model separated the two elevations along the predictive (P1) axis (Fig. 1), with significant permutation $(\mathrm{p}=0.003), \mathrm{R}^{2}(0.939)$, and $\mathrm{Q}^{2}$ (0.639) values. VIP analysis determined which metabolites distinguished high from low elevation teas. Table 1 lists the 37 the metabolites exhibiting a statistically significant difference between elevations, with 23 vs. 14 compounds higher in concentration in high vs. low 
Table 2

Statistically important metabolites in Jinuo Mountain high and low elevation tea.

\begin{tabular}{|c|c|c|c|c|c|c|}
\hline No. & Compound & VIP & $\mathrm{p}$-value & $\%$ Diff. & Aroma & Health Property \\
\hline & High Elevation & & & & & \\
\hline 278 & 2-Cyclohexen-1-ol & 2.263 & 0.003 & - & Caramelized, floral $^{\mathrm{b}}$ & \\
\hline 266 & (2E)-Hexenol & 2.215 & 0.003 & - & Green, leafy, fruity ${ }^{a}$ & \\
\hline 288 & 10 & 2.201 & 0.003 & - & & \\
\hline 176 & 1-Ethyl-1H-pyrrole-2-carboxaldehyde & 2.198 & 0.002 & 60 & Roasted, smoky ${ }^{\mathrm{a}}$ & \\
\hline 263 & endo-Fenchol & 2.188 & 0.003 & - & Camphor, pine, woody ${ }^{\mathrm{a}}$ & \\
\hline 92 & 2-Methylpentanal & 2.171 & 0.009 & 45 & Green, fruity ${ }^{a}$ & \\
\hline 44 & (Z)-Jasmone & 2.053 & 0.009 & 42 & Jasmine, floral $^{\mathrm{a}}$ & Antibacterial $^{\mathrm{f}}$ anticancer $^{\mathrm{g}}$ \\
\hline 178 & Benzeneacetonitrile & 2.043 & 0.002 & 46 & Floral $^{\mathrm{c}}$ & \\
\hline 127 & $m$-Xylene & 1.984 & 0.02 & 47 & Plastic $^{\mathrm{a}}$ & \\
\hline 131 & $o$-Xylene & 1.969 & 0.009 & 44 & Geranium $^{\mathrm{a}}$ & \\
\hline 128 & $p$-Xylene & 1.965 & 0.02 & 46 & Sweet, grain ${ }^{\mathrm{d}}$ & \\
\hline 135 & 1,2,4-Trimethylbenzene & 1.960 & 0.04 & 38 & Plastic $^{\mathrm{a}}$ & \\
\hline 213 & 1 & 1.928 & 0.009 & 43 & & \\
\hline 145 & Dehydro-ar-ionene & 1.839 & 0.04 & 49 & Licorice $^{\mathrm{a}}$ & \\
\hline 124 & Toluene & 1.830 & 0.01 & 56 & Sweet, paint ${ }^{\mathrm{a}}$ & \\
\hline 297 & 42 & 1.830 & 0.003 & - & & \\
\hline 146 & $\alpha$-Ionene & 1.823 & 0.04 & 58 & Floral, violet ${ }^{\mathrm{e}}$ & \\
\hline 144 & Theaspirane & 1.818 & 0.04 & 34 & Tea, herbal, honey ${ }^{\mathrm{a}}$ & \\
\hline 52 & (E)-Caryophyllene & 1.802 & 0.009 & 36 & Green, spicy, woody ${ }^{a}$ & Analgesic ${ }^{\mathrm{h}, \mathrm{i}}$ anticancer ${ }^{\mathrm{h}}$ antianxiety, Antidepressant ${ }^{\mathrm{i}}$ anti-inflammatory ${ }^{\mathrm{j}}$ \\
\hline 201 & Methyl salicylate & 1.785 & 0.01 & 41 & Wintergreen $^{\mathrm{a}}$ & Anti-inflammatory, analgesic ${ }^{\mathrm{k}}$ \\
\hline 111 & 2,2,6-Trimethylcyclohexanone & 1.744 & 0.03 & 48 & Honey, floral ${ }^{\mathrm{a}}$ & \\
\hline 259 & 64 & 1.742 & 0.03 & 39 & & \\
\hline 125 & 5,5-Dimethyl-1-ethyl-1,3-cyclopentadiene & 1.682 & 0.01 & 43 & & \\
\hline \multirow[t]{2}{*}{77} & $n$-Hexanol & 1.635 & 0.03 & 44 & Green, fruity, apple ${ }^{a}$ & Anti-stress ${ }^{1}$ \\
\hline & Low Elevation & & & & & \\
\hline 290 & 17 & 2.050 & 0.003 & - & & \\
\hline 268 & 2,6-Dimethyl-3,7-octadiene-2,6-diol & 1.841 & 0.01 & - & Fruity, herbal $^{\mathrm{f}}$ & \\
\hline 237 & 36 & 1.818 & 0.04 & -72 & & \\
\hline 275 & Isovaleric acid & 1.804 & 0.02 & -123 & Cheesy, rancid ${ }^{\mathrm{a}}$ & \\
\hline 16 & Dehydro-1,8-cineole & 1.753 & 0.009 & -113 & Mint, lemon ${ }^{\mathrm{a}}$ & \\
\hline 27 & cis-Linalool oxide (pyranoid) & 1.709 & 0.03 & -92 & Citrus, green ${ }^{a}$ & \\
\hline 302 & 67 & 1.650 & 0.01 & - & & \\
\hline 257 & 61 & 1.580 & 0.02 & -98 & & \\
\hline 299 & 48 & 1.565 & 0.04 & -72 & & \\
\hline 236 & 35 & 1.564 & 0.03 & -66 & & \\
\hline 162 & Hexanoic acid & 1.550 & 0.04 & -578 & Fatty, sweaty, cheesy ${ }^{\mathrm{a}}$ & \\
\hline 29 & trans-Linalool oxide (pyranoid) & 1.535 & 0.03 & -81 & Woody, floral $^{\mathrm{a}}$ & \\
\hline 291 & 21 & 1.521 & 0.01 & -91 & & \\
\hline 305 & 76 & 1.521 & 0.01 & - & & \\
\hline 107 & Cyclohexanone & 1.491 & 0.01 & -141 & Minty $^{\mathrm{a}}$ & \\
\hline 232 & 29 & 1.426 & 0.03 & -336 & & \\
\hline 23 & Hotrienol & 1.307 & 0.04 & -60 & Floral, woody ${ }^{\mathrm{a}}$ & \\
\hline 276 & 2-Methylbutanoic acid & 1.242 & 0.03 & -259 & Fruity, cheesy, sweaty ${ }^{\mathrm{a}}$ & \\
\hline 262 & 68 & 1.075 & 0.03 & -301 & & \\
\hline
\end{tabular}

Notes:

1. OPLS-DA criteria used to determine compound differences between high and low elevation teas: VIP $>1.0$ and $\mathrm{p}$ value $<0.05$.

2. $\%$ Diff. $=[($ High-Low $) /$ High $] \times 100$.

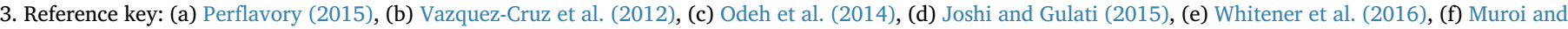
Kubo (1993), (g) Tong et al. (2008), (h) Fidyt et al. (2016), (i) Bahi et al. (2014), (j) Klauke et al. (2014), (k) Higashi et al. (2010), and (1) Kako et al. (2008).

4. Numbers in the compound column refer to unknown analytes.

elevation teas.

Of the high elevation compounds, the relative peak areas of $p$-xylene, 2-cyclohexen-1-ol, benzeneacetonitrile, $(Z)$-jasmone, $\alpha$-ionene, 2 acetylfuran, and theaspirane are at least twice that of 1-ethyl-1H-pyrrole-2-carboxaldehyde, (2E)-hexenol, $(E)$-caryophyllene, (3Z)-hexenol, $\alpha$-calacorene , and 1-ethyl-1 $H$-pyrrole. The former exhibit sweet, floral, honey-like notes associated with high quality tea, (Acree \& Arn, 2004; Joshi \& Gulati, 2015; Vazquez-Cruz et al., 2012; Whitener et al., 2016) while the latter possess green, herbal, roasted, woody notes (Acree \& Arn, 2004). In comparison, statistics indicate trans-linalool oxide (pyranoid), 2,6-dimethyl-3,7-octadien-2,6-diol, (2E,4Z)-heptadienal, cyclohexanone, isovaleric acid, 2,3-dihydrobenzofuran and dihydroactinidiolide are higher in concentration and differentiate low from high elevation teas. These compounds are typically characterized as cheesy, fatty, fried, fruity, green, herbal, minty, rancid, and woody (Acree \& Arn, 2004; Bellincontro et al., 2016).
Examples of GC-GC/MS-olfactometry analysis of sensory active metabolites are shown in Figs. 2 and 3. The sample portion from 17 to $18 \mathrm{~min}$ in Fig. 2 shows two regions in the total ion current (TIC) chromatogram where odors were detected for compounds whose signals were below the baseline signal. The first was an earthy, mushroom scent and the second, sweet, floral. In Fig. 3, heartcut 19-20 min shows the TIC and reconstructed ion current chromatogram after spectral deconvolution of compound \#47, which elutes at $38.4 \mathrm{~min}$ and smells of anise. Compound \#52, also shown in the Fig. 3, coelutes with geraniol at $41.5 \mathrm{~min}$. From a sensory perspective, compound \#52 is waxy compared to the floral, rose scent of geraniol. Despite subtracting the mass spectrum of geraniol at each scan across the waxy peak to obtain a clean spectrum of compound \#52, assigning an identity was not possible. Nonetheless, evident from the OPLS-DA and GC-GC/MS-olfactometry is the fact that unidentifiable compounds that contributed to differences in high and low elevation teas were not sensory active. Tea 
Table 3

Catechin and methylxanthine concentrations in high and low elevation teas.

\begin{tabular}{|c|c|c|c|}
\hline Compound & High Elevation (mg/g tea leaf $\pm S D$ ) & Low Elevation (mg/g tea leaf $\pm S D$ ) & $\mathrm{p}$-value \\
\hline Theobromine & $2.56 \pm 0.33$ & $2.86 \pm 0.43$ & 0.1181 \\
\hline Caffeine & $33.48 \pm 3.55$ & $37.44 \pm 2.59$ & $0.0157^{*}$ \\
\hline Epigallocatechin & $9.11 \pm 2.63$ & $9.91 \pm 2.13$ & 0.4853 \\
\hline Epicatechin & $13.12 \pm 5.41$ & $15.80 \pm 3.67$ & 0.2362 \\
\hline Epigallocatechin gallate & $54.18 \pm 13.77$ & $51.98 \pm 6.75$ & 0.6718 \\
\hline Epicatechin gallate & $38.31 \pm 6.35$ & $48.18 \pm 4.18$ & $0.0013^{*}$ \\
\hline Gallocatechin & $1.54 \pm 0.19$ & $1.89 \pm 0.39$ & $0.0267^{*}$ \\
\hline Catechin & $4.33 \pm 1.44$ & $6.25 \pm 2.30$ & $0.0497^{*}$ \\
\hline Gallocatechin gallate $^{\mathrm{a}}$ & $0.62 \pm 0.10$ & $0.61 \pm 0.06$ & 0.8441 \\
\hline Catechin gallate & $0.28 \pm 0.08$ & $0.35 \pm 0.13$ & 0.2157 \\
\hline
\end{tabular}

$* p<0.05$.

${ }^{\text {a }}$ Estimated due to sub-LOQ levels.

is a complex beverage, containing hundreds of organic compounds, whose flavor, intensity, and balance are due to these and other organics.

A total of 83 volatile metabolites have reported health benefits. Of the 37 statistically important metabolites in Table 1 that differentiate high from low elevation tea, six have reported health benefits including (E)-caryophyllene (analgesic, antianxiety, antidepressant, anticancer, anti-inflammatory), (3Z)-hexenol (antifatigue, antinociceptive, antistress), (Z)-jasmone (antibacterial, anticancer), manool (antibacterial, antifungal, anti-inflammatory), $\alpha$-calacorene (antibacterial, antioxidant), and cadalene (antibacterial, antioxidant), (Aou et al., 2005; Bahi et al., 2014; Fidyt, Fiedorowicz, Strzadala, \& Szumny, 2016; Kako, Fukumoto, Kobayashi, \& Yokogoshi, 2008; Klauke et al., 2014; Muroi \& Kubo, 1993; Odeh, Abu-Lafi, \& Al-Najjar, 2014; Olivier \& Van Wyk, 2013; Rossi et al., 2011; Tong et al., 2008). In addition, 15 compounds were higher in concentration in the $1400 \mathrm{~m}$ vs. $600 \mathrm{~m}$ samples. $\gamma$-cadinene and $\gamma$-decalactone were only detected in high elevation teas. None of the 14 compounds that distinguish low elevation tea have reported health claims. Nonetheless, low elevation tea contains some health beneficial compounds higher in concentration than high elevation teas. It should be pointed out that the remaining health beneficial compound concentrations fall within $\pm 20 \%$ at the two elevations.

As expected, statistical analysis of Jinuo Mountain data revealed a significant elevational effect ( $\mathrm{p}=0.005, \mathrm{R}^{2}=0.912$, and $\mathrm{Q}^{2}=0.719$ ). Metabolites such as 1-ethyl-1 $H$-pyrrole-2-carboxaldehyde, $(Z)$-jasmone, (E)-caryophyllene, trans-linalool oxide (pyranoid), 2,6-dimethyl-3,7octadien-2,6-diol, and isovaleric acid are still identified as important differentiators of high and low elevation teas. Several additional metabolites, listed in Table 2, become important such as 2-methylpentanal, methyl salicylate, 2,2,6-trimethylcyclohexanone, dehydro-1,8cineole, hexanoic acid, and hotrienol (Acree \& Arn, 2004; Bahi et al., 2014; Fidyt et al., 2016; Higashi, Kiuchi, \& Furuta, 2010; Joshi \& Gulati, 2015; Kako et al., 2008; Klauke et al., 2014; Muroi \& Kubo, 1993; Odeh et al., 2014; Tong et al., 2008; Whitener et al., 2016).

MANOVA analysis of catechins and methylxanthines revealed a significant $(\mathrm{p}=0.0062)$ separation between high and low elevation tea (Table 3) due to the lower concentrations of ECG, GC, C and caffeine in the high elevation tea (one-way ANOVA, all $\mathrm{p}<0.05$ ). No statistical difference was observed for the other analytes. On the one hand, our findings for epicatechin gallate and gallocatechin are in agreement with other investigators (Chen et al., 2010, 2014; Han et al., 2017; Zhang et al., 2018). On the other, catechin and caffeine were not. Caffeine alone results in a lower flavor profile method bitterness ranking from slight-to-moderate (1 $1 \frac{1}{2}$ ) to slight (1); low bitterness and astringency are associated with higher quality teas (Chen et al., 2014; Han et al., 2017; Zhang et al., 2018). Nonetheless, catechins in high elevation teas are high enough in concentration to potentially provide the many health benefits associated with them (Vuong, 2014).

\section{Conclusion}

We demonstrated a $5{ }^{\circ} \mathrm{C}$ change in temperature due to elevational differences causes significant plant alterations in tea chemistry. This finding was independent of the mountain from which the teas were grown. High elevation tea contained statistically higher concentrations of volatile compounds whose health beneficial properties include analgesic, antianxiety, antibacterial, anticancer, antidepressant, antifungal, anti-inflammatory, antioxidant, anti-stress, and cardioprotective. Low elevation teas did not contain statistically higher concentrations of any health beneficial compounds. In addition, high elevation teas contained statistically sweeter, floral, honey-like compounds as opposed to low elevation tea, which contained statistically greener, herbal, hay-like, bitter compounds. Given these results and our previous studies, it is evident that the composition of tea is strikingly different due to growing conditions, which most likely accounts for inconsistencies in the outcomes of clinical trials, whose aims are to investigate the health benefits of tea, since no study includes a detailed metabolomic profile of the sample consumed by participants. Toward this end, we are developing 2-dimensional LC/MS methods with the goal of unraveling the complex metabolomic profile of polyphenolic compounds in tea. This study is part of a larger effort in understanding the complex relationships and feedback loops that occur between human and natural systems.

\section{Acknowledgements}

This work was supported by the National Science Foundation, United States Grant BCS-1313775. The authors also appreciate the support of Gerstel GmbH, Gerstel USA, Agilent Technologies, and Ion Analytics for providing the instruments and software to analyze samples.

\section{Conflict of interests}

Dr. Robbat is the founder of Ion Analytics.

\section{References}

Acree, T., \& Arn, H. (2004). Flavornet and human odor space. Geneva, NY: Cornell University.

Ahmed, S., \& Stepp, J. R. (2012). Green tea: The plants, processing, manufacturing and production. In V. Preedy (Ed.). Tea in health and disease prevention. London, UK: Academic Press.

Ahmed, S., Stepp, J. R., Orians, C., Griffin, T., Matyas, C., Robbat, A., Jr, ... Kennelly, E. (2014). Effects of extreme climate events on tea (Camellia sinensis) functional quality 
validate indigenous farmer knowledge and sensory preferences in tropical China. PLoS One, 9(10), e109126.

Aou, S. J., Mizuno, M., Matsunaga, Y., Kubo, K., Li, X. L., \& Hatanaka, A. (2005). Green odor reduces pain sensation and fatigue-like responses without affecting sensorimotor function. Chemical Senses, 30, I262-i263. http://dx.doi.org/10.1093/chemse/ bjh215.

ASTM (1992). Manual on descriptive anlysis testing for sensory evaluation. The flavor profile method, vol. MNL 13.

Babushok, V. I., Linstrom, P. J., \& Zenkevich, I. G. (2011). Retention indices for frequently reported compounds of plant essential oils. Journal of Physical and Chemical Reference Data, 40(4).

Bahi, A., Al Mansouri, S., Al Memari, E., Al Ameri, M., Nurulain, S. M., \& Ojha, S. (2014). beta-Caryophyllene, a CB2 receptor agonist produces multiple behavioral changes relevant to anxiety and depression in mice. Physiology \& Behavior, 135, 119-124. http://dx.doi.org/10.1016/j.physbeh.2014.06.003.

Bellincontro, A., Matarese, F., D'Onofrio, C., Accordini, D., Tosi, E., \& Mencarelli, F. (2016). Management of postharvest grape withering to optimise the aroma of the final wine: A case study on Amarone. Food Chemistry, 213, 378-387.

Chen, G.-H., Yang, C.-Y., Lee, S.-J., Wu, C.-C., \& Tzen, J. T. C. (2014). Catechin content and the degree of its galloylation in oolong tea are inversely correlated with cultivation altitude. Journal of Food and Drug Analysis, 22, 303-309.

Chen, Y., Jiang, Y., Duan, J., Shi, J., Xue, S., \& Kakuda, Y. (2010). Variation in catechin contents in relation to quality of 'Huang Zhi Xiang' Oolong tea (Camellia sinensis) at various growing altitudes and seasons. Food Chemistry, 119(2), 648-652.

Fidyt, K., Fiedorowicz, A., Strzadala, L., \& Szumny, A. (2016). Beta-caryophyllene and beta-caryophyllene oxide-natural compounds of anticancer and analgesic properties. Cancer Medicine, 5(10), 3007-3017. http://dx.doi.org/10.1002/cam4.816.

Han, W.-Y., Huang, J.-G., Li, X., Li, Z.-X., Ahammed, G. J., Yan, P., \& Stepp, J. R. (2017). Altitudinal effects on the quality of green tea in east China: A climate change perspective. European Food Research and Technology, 243, 323-330.

Higashi, Y., Kiuchi, T., \& Furuta, K. (2010). Efficacy and safety profile of topical methyl salicylate and menthol patch in adult patients with mild to moderate muscle strain: A randomized, double-blind, parallel-group, placebo-controlled, multicenter study. Clinical Therapeutics, 32(1), 34-43.

Holopainen, J. K., \& Gershenzon, J. (2010). Multiple stress factors and the emission of plant VOCs. Trends in Plant Science, 15(3), 176-184.

Joshi, R., \& Gulati, A. (2015). Fractionation and identification of minor and aroma-active constituents in Kangra orthodox black tea. Food Chemistry, 167, 290-298. http://dx. doi.org/10.1016/j.foodchem.2014.06.112.

Kako, H., Fukumoto, S., Kobayashi, Y., \& Yokogoshi, H. (2008). Effects of direct exposure of green odour components on dopamine release from rat brain striatal slices and PC12 cells. Brain Research Bulletin, 75, 706-712.

Kalili, K. M., \& de Villiers, A. (2010). Off-line comprehensive two-dimensional hydrophilic interaction $\times$ reversed phase liquid chromatographic analysis of green tea phenolics. Journal of Separation Science, 33(6-7), 853-863.

Kang, Y., Khan, S., \& Ma, X. (2009). Climate change impacts on crop yield, crop water productivity and food security - A review. Progress in Natural Science, 19, 1665-1674.

Klauke, A. L., Racz, I., Pradier, B., Markert, A., Zimmer, A. M., Gertsch, J., \& Zimmer, A. (2014). The cannabinoid CB2 receptor-selective phytocannabinoid beta-caryophyllene exerts analgesic effects in mouse models of inflammatory and neuropathic pain. European Neuropsychopharmacology, 24(4), 608-620. http://dx.doi.org/10. 1016/j.euroneuro.2013.10.008.

Kowalsick, A., Kfoury, N., Robbat, A., Jr, Ahmed, S., Orians, C., Griffin, T., ... Stepp, J. R. (2014). Metabolite profiling of Camellia sinensis by automated sequential, multidimensional gas chromatography/mass spectrometry reveals strong monsoon effects on tea constituents. Journal of Chromatography A, 1370, 230-239.

Kurukulasuriya, P., \& Rosenthal, S. (2013). Climate change and agriculture: a review of impacts and adaptations. Climate change series, vol. 91.

Li, Y.-S., Kawasaki, Y., Tomita, I., \& Kawai, K. (2017). Antioxidant properties of green tea aroma in mice. Journal of Clinical Biochemistry and Nutrition, 61(1), 14-17.

Mahanta, P. K., Baruah, S., Owour, P. O., \& Murai, T. (1988). Flavour volatiles of Assam
CTC black teas manufactured from different plucking standards and orthodox teas manufactured from different altitudes of Darjeeling. Journal of the Science of Food and Agriculture, 45(4), 317-324.

Muroi, H., \& Kubo, I. (1993). Combination effects of antibacterial compounds in green tea flavor against Streptococcus-mutans. Journal of Agricultural and Food Chemistry, 41(7), 1102-1105. http://dx.doi.org/10.1021/jf00031a017.

NOAA (2017). Environmental temperature lapse rate. http://www.spc.noaa.gov/exper/ soundings/help/lapse.html.

Odeh, I., Abu-Lafi, S., \& Al-Najjar, I. (2014). Determination of unifloral honey volatiles from Centaurea iberica and Zizyphus spinachristi by solid-phase microextraction and gas chromatography-mass spectrometry. Acta Chromatographica, 26(3), 485-493. http://dx.doi.org/10.1556/AChrom.26.2014.3.7.

Olivier, D. K., \& Van Wyk, B. E. (2013). The major diterpenoids of the genus Arctopus (Apiaceae) with notes on their chemotaxonomic and medicinal significance. South African Journal of Botany, 85, 94-98. http://dx.doi.org/10.1016/j.sajb.2013.01.002.

Owuor, P. O., Obaga, S. O., \& Othieno, C. O. (1990). The effects of altitude on the chemical composition of black tea. Journal of the Science of Food and Agriculture, 50(1), 9-17.

Perflavory (2015). The Good Scents Company. www.thegoodscentscompany.com.

R (2014). R: A language and environment for statistical computing. Vienna, Austria: R Foundation for Statistical Computing.

Robbat, A., Jr, Kfoury, N., Baydakov, E., \& Gankin, Y. (2017). Optimizing targeted/untargeted metabolomics by automating gas chrromatography/mass spectrometry workflows. Journal of Chromatography A, 1505, 96-105.

Rossi, D., Guerrini, A., Maietti, S., Bruni, R., Paganetto, G., Poli, F., ... Sacchetti, G. (2011). Chemical fingerprinting and bioactivity of Amazonian Ecuador Croton lechleri Mull. Arg. (Euphorbiaceae) stem bark essential oil: A new functional food ingredient? Food Chemistry, 126(3), 837-848. http://dx.doi.org/10.1016/j.foodchem.2010.11. 042.

Shepherd, T., \& Griffiths, D. W. (2006). The effects of stress on plant cuticular waxes. New Phytologist, 171, 469-499.

Takahashi, A., Watanabe, T., Fujita, T., Hasegawa, T., Saito, M., \& Suganuma, M. (2014). Green tea aroma fraction reduces $\beta$-amyloid peptide-induced toxicity in Caenhorhabditis elegans transfected with human $\beta$-amyloid minigene. Bioscience, Biotechnology, and Biochemistry, 78(7), 1206-1211.

Thèvenot, E. A., Roux, A., Xu, Y., Exan, E., \& Junot, C. (2015). Analysis of the humnan adult urinary metabolome variations with age, body mass index, and gender by im plementing a comprehensive workflow for univariate and OPLS statistical analyses. Journal of Proteome Research, 14(8), 3322-3335.

Tong, Q. S., Jiang, G. S., Zheng, L. D., Tang, S. T., Cai, J. B., Liu, Y., ... Dong, J. H. (2008). Natural jasmonates of different structures suppress the growth of human neuroblastoma cell line SH-SY5Y and its mechanisms. Acta Pharmacologica Sinica, 29(7), 861-869. http://dx.doi.org/10.1111/j.1745-7254.2008.00814.x.

Trad, M., Gaaliche, B., Renard, C. M. G. C., \& Mars, M. (2013). Inter- and intra-tree variability in quality of figs. Influence of altitude, leaf area and fruit position in the canopy. Scientia Horticulturae, 162, 49-54.

Vazquez-Cruz, M. A., Jimenez-Garcia, S. N., Torres-Pacheco, I., Guzman-Maldonado, S H., Guevara-Gonzalez, R. G., \& Miranda-Lopez, R. (2012). Effect of maturity stage and storage on flavor compounds and sensory description of berrycactus (Myrtillocactus geometrizans). Journal of Food Science, 77(4), C366-C373. http://dx. doi.org/10.1111/j.1750-3841.2012.02621.x.

Vuong, Q. V. (2014). Epidemiological evidence linking tea consumption to human health: A review. Critical Reviews in Food Science and Nutrition, 54(4), 523-536.

Whitener, M. E. B., Stanstrup, J., Panzeri, V., Carlin, S., Divol, B., Du Toit, M., \& Vrhovsek, U. (2016). Untangling the wine metabolome by combining untargeted SPME-GCxGCTOF-MS and sensory analysis to profile Sauvignon blanc co-fermented with seven different yeasts. Metabolomics, 12(3), 25. http://dx.doi.org/10.1007/s11306-0160962-4.

Zhang, C., Suen, C. L.-C., Yang, C., \& Quek, S. Y. (2018). Antioxidant capacity and major polyphenol composition of teas as affected by geographical location, plantation elevation and leaf grade. Food Chemistry, 244, 109-119. 